Commi ssi oni ng Test Results of Vari abl e Temper at ure Hel i um Ref $r$ i ger at or / Li quef i er for N FS Super conduct ing Nagnet Test Faci l ity

\begin{tabular}{|l|l|}
\hline $\begin{array}{l}\text { j our nal or } \\
\text { publ i cat } i \text { on } \mathrm{t} \text { i t I e }\end{array}$ & I EEE Transact i ons on Appl i ed Super conduct i vi ty \\
\hline vol une & 26 \\
\hline number & 3 \\
\hline page r ange & 9500404 \\
\hline year & $2016-02-04$ \\
\hline NAI S & 10371 \\
\hline URL & ht t p: //hdl . handl e. net $/ 10655 / 00012578$ \\
\hline
\end{tabular}




\title{
Commissioning Test Results of Variable Temperature Helium Refrigerator/Liquefier for NIFS Superconducting Magnet Test Facility
}

\author{
S. Hamaguchi, A. Iwamoto, K. Takahata, S. Takada, S. Imagawa, T. Mito, S. Moriuchi, K. Oba, S. Takami, \\ H. Higaki, T. Kumaki and K. Nadehara
}

\begin{abstract}
The superconducting magnet test facility in the National Institute for Fusion Science has been upgraded for excitation tests at a wide temperature range and a higher magnetic field of $13 \mathrm{~T}$. As part of the upgrade, the helium refrigerator/liquefier operated for 24 years was replaced with a variable temperature helium refrigerator/liquefier. The required liquefaction rate is $250 \mathrm{~L} / \mathrm{h}$ and the required refrigeration capacity is $600 \mathrm{~W}$ at $4.5 \mathrm{~K}$ as the previous one. Besides, it has a new feature that can supply helium gas of a wide temperature range. The typical design cooling capacity is $1 \mathrm{~kW}$ under the condition of $20 \mathrm{~K}$ supply/30 K return and $1.5 \mathrm{~kW}$ under the condition of $40 \mathrm{~K}$ supply/50 K return. After the replacement, a series of commissioning tests were performed under the various operational conditions. From the results, the satisfactory thermodynamic performance was confirmed. In the future, it is expected that the substantial progress will be made in the development of large scale superconducting magnets with advanced superconductors such as high temperature superconductors and $\mathrm{MgB}_{2}$. The design of the variable temperature helium refrigerator/liquefier and the results of the commissioning tests are reported in detail.
\end{abstract}

Index Terms-helium refrigerator/liquefier, commissioning test, variable temperature, superconducting magnet, test facility.

\section{INTRODUCTION}

$\mathrm{T}$ HE SUPERCONDUCTING MAGNET TEST FACILITY was constructed in the National Institute for Fusion Science (NIFS) to develop large scale superconducting magnets primarily for the Large Helical Device (LHD) [1]. The facility consists of a helium cryogenic system with the cooling capacity of $600 \mathrm{~W}$ at $4.5 \mathrm{~K}$, large experimental cryostats with the maximum bias field of $9 \mathrm{~T}$, DC power supplies with the maximum current of $75 \mathrm{kA}$ and a distributed control system [2], [3]. In the past, the development of the superconductors and the superconducting magnets for the helical coils (HC) and the poloidal coils (PC) of the LHD, a lot of excitation tests and various collaborative research efforts have successfully been carried out in the facility [4]-[11].

It is proposed from the standpoint of higher magnetic field and less activation that high temperature superconductors

S. Hamaguchi, A. Iwamoto, K. Takahata, S. Takada, S. Imagawa, T. Mito, S. Moriuchi, K. Oba and S. Takami are with National Institute for Fusion Science, 322-6 Oroshi, Toki, Gifu 509-5292 Japan (e-mail: hamaguchi@LHD.nifs.ac.jp).

H. Higaki, T. Kumaki and K. Nadehara are with Taiyo Nippon Sanso Corporation, 6-2 Kojima, Kawasaki, Kanagawa 210-0861 Japan.
(HTS) and $\mathrm{MgB}_{2}$ will be applied to superconducting magnets and applications for fusion reactors and accelerators in the future [12]-[14]. Therefore, the test facility with higher bias field is required and the helium cryogenic system which can supply coolant of wide temperature range is also desired because the magnets and applications have a potential to be operated above liquid helium temperature.

In Japanese Fiscal Year (JFY) of 2014, the helium cryogenic system of the NIFS superconducting magnet test facility was partially updated for excitation tests of superconductors and superconducting magnets with HTS and $\mathrm{MgB}_{2}$. In the update, the main compressor, the helium refrigerator/liquefier and the control system, which had been operated since 1991, were replaced. The new helium refrigerator/liquefier has not only the same cooling capacity as the old one but also the function that allows supply of helium gas of variable temperature in order to investigate the characteristics of superconductors and superconducting magnets under various temperatures [11]. The new control system similar to the duplicated control system of the cryogenic system for the LHD is adopted with the object of reliability and maintainability [15]. Besides, a superconducting magnet of solenoid winding with the bore diameter of $700 \mathrm{~mm}$ and the maximum field of $13 \mathrm{~T}$ was fabricated in order to conduct excitation tests under the high magnetic field [16]. It is expected that the R \& D of superconducting magnets and applications for future fusion reactors and accelerators will be promoted strongly. In this paper, the update of the cryogenic system for the NIFS superconducting magnet test facility is reported. Especially,

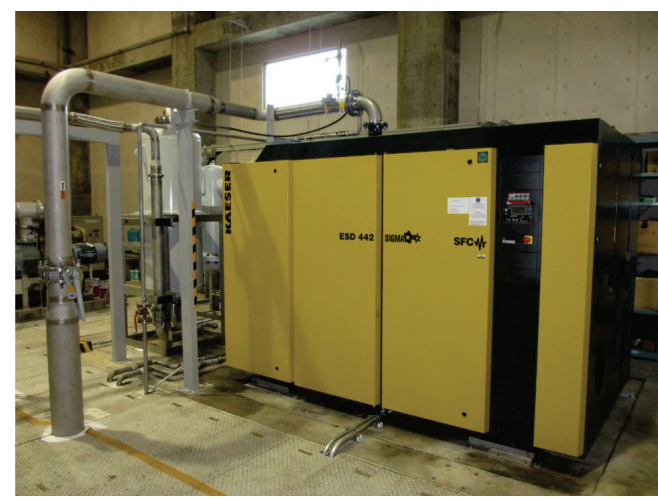

Fig. 1. Photograph of the new main compressor. The oil removal system is installed beyond the compressor. 
the modified design of the variable temperature helium refrigerator/liquefier is described and results of the commissioning tests are reported in detail.

\section{Renewed DeVices in Helium CRYogenic System}

\section{A. Main Compressor}

The previous compressor of Kobe Steel, Ltd. with the discharge pressure of $1.52 \mathrm{MPaG}$ and the mass flow rate of $99.2 \mathrm{~g} / \mathrm{s}$ has been replaced with an oil injection type screw compressor of Kaeser Kompressoren $\mathrm{GmbH}$ with the discharge pressure of $0.95 \mathrm{MPaG}$ and the mass flow rate of $101.7 \mathrm{~g} / \mathrm{s}$. The electric power consumption is reduced from $450 \mathrm{~kW}$ to $239 \mathrm{~kW}$. An oil removal system in the downstream and a valve unit for adjustment of the circulating flow rate of the helium cryogenic system are equipped by Taiyo Nippon Sanso Corporation. Fig. 1 is a photograph of the main compressor in the compressor room.

The major part of the helium cryogenic system is excluded by the application of the High Pressure Gas Safety Act in Japan because the discharge pressure is less than $1 \mathrm{MPaG}$. Thus, the maintenance can be simplified and the prompt repair can be performed. As the result, the running cost will be reduced and the availability will be improved.

\section{B. Variable Temperature Helium Refrigerator/Liquefier}

An LR280 of Linde Kryotechnik AG with the same cooling capacity of $600 \mathrm{~W}$ at $4.5 \mathrm{~K}$ as the previous helium refrigerator/liquefier of Kobe Steel, Ltd. was installed in the helium cryogenic system for the NIFS superconducting magnet test facility. Fig. 2 is a photograph of the cold box in the main laboratory and Fig. 3 shows its flow diagram during a series of the commissioning tests.

It consists of two stage of expansion turbines with dynamic gas bearing, two internal absorbers ( $80 \mathrm{~K}$ and $20 \mathrm{~K}$ ), a gasliquid separator with a heater to control the liquid helium level,

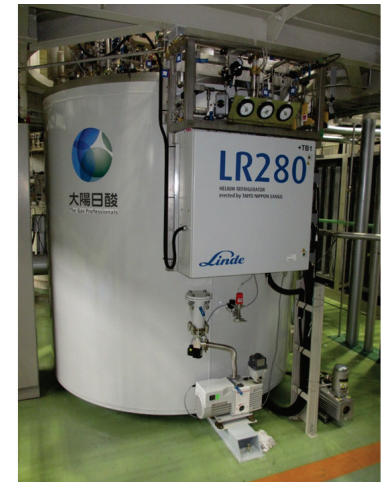

Fig. 2. Photograph of the variable temperature helium refrigerator/liquefier.

eight aluminium plate-fin heat exchangers and a lot of cryogenic valves. In the liquefaction mode, the inlet pressure of the cold box is $0.86 \mathrm{MPaG}$ and the mass flow rate is 89.0 $\mathrm{g} / \mathrm{s}$. The Joule-Thomson expansion pressure is $0.83 \mathrm{MPaG}$, while the pressure in the external LHe dewar is $0.024 \mathrm{MPaG}$. The rotational speed of the first and second turbine is around $170 \mathrm{krpm}$ and $110 \mathrm{krpm}$, respectively.

An external heater unit to warm helium gas returned to the suction of the main compressor and an external pump to vacuum the thermal insulation vessel are equipped. Liquid helium (LHe), supercritical helium (SHe) and variable temperature helium gas (VT-GHe) can be output. Dummy heater units were attached on the supply/return ports of supercritical helium and variable temperature helium gas to measure the cooling capacity in the commissioning tests (see the right ends of Fig. 3).

The required helium liquefaction rate is $250 \mathrm{~L} / \mathrm{h}$ in pure liquefaction mode and the required cooling capacity at $4.5 \mathrm{~K}$ is $600 \mathrm{~W}$ in pure refrigeration mode. In the case of supercritical helium, the required mass flow rate without liquefaction is 50 $\mathrm{g} / \mathrm{s}$ with the cooling capacity of $350 \mathrm{~W}$ at $4.55 \mathrm{~K}$. The new refrigerator/liquefier has the function that can supply the

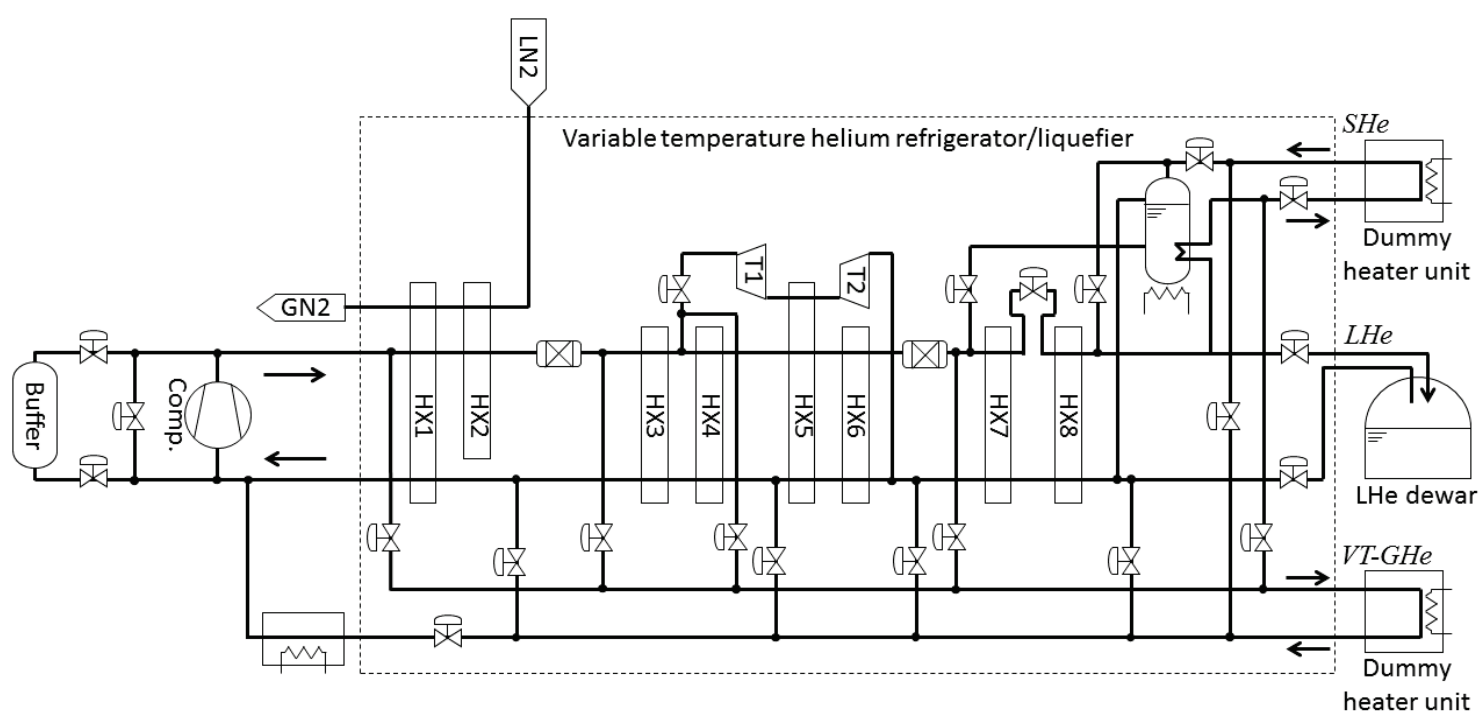

Fig. 3. Flow diagram of the variable temperature helium refrigerator/liquefier with two dummy heater units for the commissioning test. 


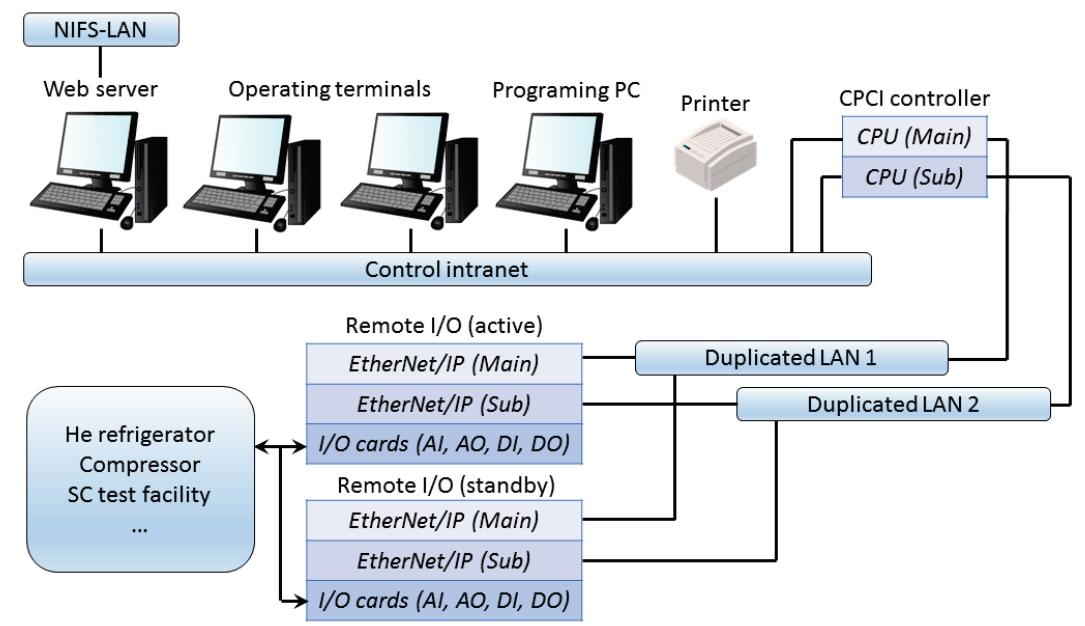

Fig. 4. Configuration of the control system of the helium cryogenic system for the NIFS superconducting magnet test facility.

helium gas at wide temperature range without liquefaction. As typical design, the cooling capacity is $1 \mathrm{~kW}$ when the supply temperature is $20 \mathrm{~K}$ and the return temperature $30 \mathrm{~K}$ while it is $1.5 \mathrm{~kW}$ when the supply temperature is $40 \mathrm{~K}$ and the return temperature is $50 \mathrm{~K}$. In all conditions above, liquid nitrogen (LN2) are used as auxiliary cryogen.

\section{Cryogenic Control System}

The control system for the helium cryogenic system has also been renewed in order to simplify the system configuration and to improve the reliability and maintainability of the system. The configuration similar to the control system for the LHD cryogenic system has been adopted and is shown in Fig. 4 [15].

A controller was changed from discontinued micro-XL of Yokogawa Electric Corporation into DeMPICS of Taiyo Nippon Sanso Corporation. It is connected to remote I/O with EtherNet/IP and CPU of the controller, LAN and remote I/O are doubled, respectively. The control system has four personal computers (PC) as human interface and those are two operating terminals, a programing $\mathrm{PC}$ and a web server. The web server is connected to the NIFS-LAN and remote monitoring can be provided for improvement of safety and convenience.

\section{Commissioning Test}

\section{A. Test Methods}

After the update of the cryogenic system had been completed, the purifying operation of the helium cryogenic system had been done and then a series of the commissioning tests had been performed. The tested conditions are as follows; (1) helium liquefaction rate, (2) cooling capacity at $4.5 \mathrm{~K}$, (3) cooling capacity at supply temperature of $20 \mathrm{~K}$ and return temperature of $30 \mathrm{~K}$ (at $20 \mathrm{~K} / 30 \mathrm{~K}$ ), (4) cooling capacity at supply temperature of $40 \mathrm{~K}$ and return temperature of $50 \mathrm{~K}$ (at $40 \mathrm{~K} / 50 \mathrm{~K}$ ) and (5) mass flow rate and cooling capacity of supercritical helium.
In the liquefaction test, increase of the liquid helium level in the LHe dewar of $10,000 \mathrm{~L}$ was measured. In the cooling capacity test at $4.5 \mathrm{~K}$, electric power of the heater in the gasliquid separator was measured when the liquid helium level in the separator was kept constant by the heater. In the cooling capacity tests at $20 \mathrm{~K} / 30 \mathrm{~K}$ and $40 \mathrm{~K} / 50 \mathrm{~K}$, helium gas of $20 \mathrm{~K}$ or $40 \mathrm{~K}$ which was made by mixing helium gas after HX3 with helium gas after HX6 was supplied to the dummy heater unit of the VT-GHe port and then the return gas was returned to the low pressure line between HX4 and HX5. In the test of $\mathrm{SHe}$, the dummy heater unit of the SHe port was provided with $\mathrm{SHe}$ at $0.79 \mathrm{MPaG}$ cooled down to $4.42 \mathrm{~K}$ by heat exchange with saturated liquid helium in the gas-liquid separator and then the return $\mathrm{SHe}$ was flashed into the separator in order to be utilized for the heat exchange. In the last three tests, electric power of the dummy heaters was measured when the variable temperature helium refrigerator/liquefier was operated at steady state with constant power of the dummy heater. And also, mass flow rate was estimated by dividing heat input of the dummy heater by enthalpy difference of SHe between the inlet and outlet of the unit.

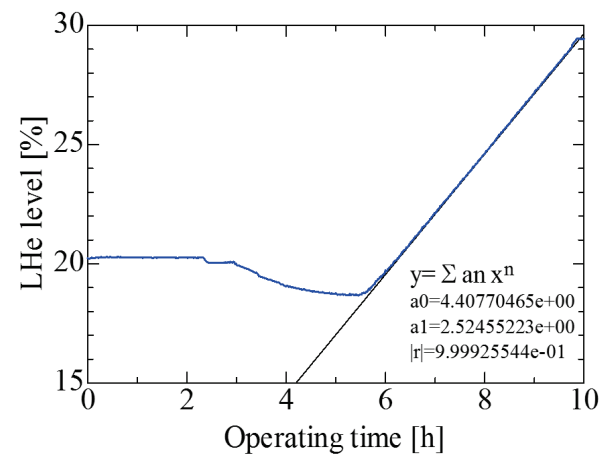

Fig. 5. Change of the liquid helium level in the LHe dewar of 10,000 L during the liquefaction test. 


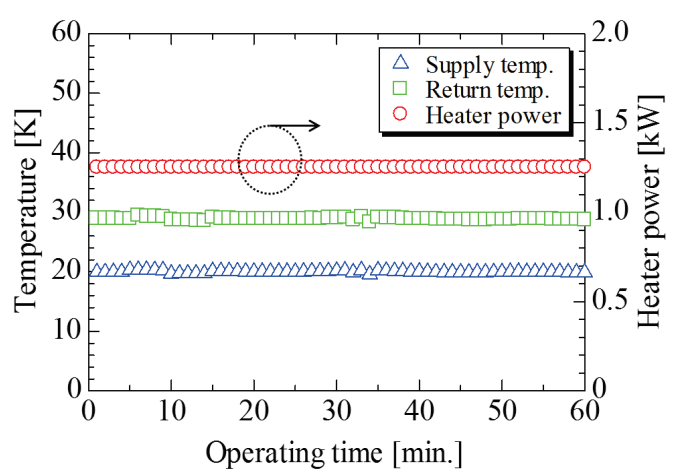

Fig. 6. Supply/return temperature of helium gas and the heat input from the dummy heater during the cooling capacity test at $20 \mathrm{~K} / 30 \mathrm{~K}$. Open triangles show the supply temperature, open squares return temperature and open circles the electric power of the dummy heater.

TABLE I

Performance of VARIABle TeMPerature Helium REFRIGERATOR/LIQUEFIER

\begin{tabular}{ccc}
\hline \hline Tested condition & Required performance & Measured performance \\
\hline Liquefaction rate & $250 \mathrm{~L} / \mathrm{h}$ & $275.5 \mathrm{~L} / \mathrm{h}$ \\
Cooling capacity & $600 \mathrm{~W}$ & $675 \mathrm{~W}$ \\
$@ 4 \mathrm{~K}$ & & $@ 4.36 \mathrm{~K}$ \\
Cooling capacity & $1 \mathrm{~kW}, 18 \mathrm{~g} / \mathrm{s}$ & $1193 \mathrm{~W}, 25 \mathrm{~g} / \mathrm{s}$ \\
$@ 20 \mathrm{~K} / 30 \mathrm{~K}$ & $@ 20 \mathrm{~K} / 30 \mathrm{~K}$ & $@ 20 \mathrm{~K} / 29 \mathrm{~K}$ \\
Cooling capacity & $1.5 \mathrm{~kW}, 20 \mathrm{~g} / \mathrm{s}$ & $1603 \mathrm{~W}, 33 \mathrm{~g} / \mathrm{s}$ \\
$@ 40 \mathrm{~K} / 50 \mathrm{~K}$ & $@ 40 \mathrm{~K} / 50 \mathrm{~K}$ & $@ 40 \mathrm{~K} / 49.3 \mathrm{~K}$ \\
$\mathrm{SHe}$ & $350 \mathrm{~W}, 50 \mathrm{~g} / \mathrm{s}$ & $407 \mathrm{~W}, 51.3 \mathrm{~g} / \mathrm{s}$ \\
& $@ 4.55 \mathrm{~K}$ & $@ 4.42 \mathrm{~K}$ \\
\hline
\end{tabular}

\section{B. Test Results}

As to the first tested condition above, Fig. 5 shows change of liquid helium level in the dewar. After start of the test, the level decreased once and then the level increased at a constant rate approximately. The constant increase rate was $2.52 \%$ per hour, corresponding to $275.5 \mathrm{~L} / \mathrm{h}$, from the least-squares method. The liquefaction rate more than the required rate of $250 \mathrm{~L} / \mathrm{h}$ was confirmed.

The test result of the cooling capacity at $20 \mathrm{~K} / 30 \mathrm{~K}$, which is the third tested condition above, was reported as the representative cooling capacity of the helium refrigerator/liquefier. The test was demonstrated by suppling helium gas at $20 \mathrm{~K}, 0.31 \mathrm{MPaG}$ to the dummy heater unit with constant heat input of $1,193 \mathrm{~W}$ from the supply port of the variable temperature helium. Fig. 6 shows the supply/return temperature of helium gas and the electric power of dummy heater. It was observed that the return temperature became constant at $29 \mathrm{~K}$. As a result, the cooling capacity at $20 \mathrm{~K} / 30$ $\mathrm{K}$ is estimated to be more than $1,193 \mathrm{~W}$.

With regard to the other tested conditions, the commissioning tests were similarly performed. All test results are summarized in Table I. Consequently, the specifications of the variable temperature helium refrigerator/liquefier have been satisfied and the excellent performance of the updated helium cryogenic system for the NIFS superconducting magnet test facility has been confirmed.

\section{CONCLUSION}

The helium cryogenic system for the NIFS superconducting magnet test facility have been updated partially. In particular, the variable temperature helium refrigerator/liquefier with the function that can supply helium gas at wide temperature range was installed in order to conduct the excitation tests at various temperatures for applying $\mathrm{HTS}$ and $\mathrm{MgB}_{2}$ to the superconducting magnets and applications. A series of the commissioning tests were conducted for five conditions and the test results were satisfactory. The large bore high magnetic field test cryostat is scheduled to be assembled in JFY 2015-2016, utilizing the $13 \mathrm{~T}$ superconducting magnet with the bore of $700 \mathrm{~mm}$. It is expected that the development of the large scale high magnetic field superconducting magnets for fusion reactors and accelerators in future and various applied research on HTS and $\mathrm{MgB}_{2}$ will be advanced significantly.

\section{REFERENCES}

[1] J. Yamamoto et al., "Superconducting test facility of NIFS for the Large Helical Device," Fusion Engineering and Design, vol. 20, Jan. 1993, pp. 147-151.

[2] J. Yamamoto et al., "A Cryogenic System for the Superconducting Magnet Testing Facility," Advances in Cryogenic Engineering, vol. 37, 1992, pp. 755-762.

[3] S. Yamada et al., "Charcteristics of a dc $75 \mathrm{kA}$ power supply in the superconducting magnet test facilities," Fusion Engineering and Design, vol. 20, Jan. 1993, pp. 201-209.

[4] J. Yamamoto et al., "Research and development of superconductors and superconducting coils for the Large Helical Device," Fusion Engineering and Design, vol. 20, Jan. 1993, pp. 139-146.

[5] K. Takahata et al., "Excitation test results on a single inner vertical coil for the Large Helical Device," IEEE Trans. Appl. Supercond., vol. 7, no. 2, Jun. 1997, pp. 477-480.

[6] N. Yanagi et al., "Development and quality control of the superconductors for the helical coils of LHD," Fusion Engineering and Design, vol. 41, no. 1-4, Sep. 1998, pp. 241-246.

[7] S. Imagawa et al., "Improvement in Cryogenic Stability of the Model Coil of the LHD Helical Coil by Lowering the Temperature," IEEE Trans. Appl. Supercond., vol. 16, no. 2, Jun. 2006, pp. 755-758.

[8] T. Mito et al., "Applied superconductivity and cryogenic research activities in NIFS," Fusion Engineering and Design, vol. 81, no. 20-22, Nov. 2006, pp. 2389-2400.

[9] S. Ito et al., "Performance of a Mechanical Bridge Joint for 30-kA-class High-temperature Superconducting Conductors," IEEE Trans. Appl. Supercond., vol. 24, no. 3, Jun. 2014, Art. ID. 4602305.

[10] H. Murakami et al., "Development and Test of JT-60SA Central Solenoid Model Coil," IEEE Trans. Appl. Supercond., vol. 24, no. 3, Jun. 2014, Art. ID. 4200205.

[11] S. Hamaguchi et al., "Upgrade Plan on NIFS Superconducting Magnet Test Facility," Plasma and Fusion Research, vol. 10, Mar. 2015, Art. ID. 3405020.

[12] N. Yanagi et al., "Design and development of high-temperature superconducting magnet system with joint-winding for the helical fusion reactor," Nuclear Fusion, vol. 55, no. 5, Apr. 2015, Art. ID. 053021.

[13] Y. Hishinuma et al., "Development of $\mathrm{MgB}_{2}$ superconducting wire for the low activation superconducting magnet system operated around core D-T plasma," Fusion Engineering and Design, to be published.

[14] G.A. Kirby et al., "Accelerator-Quality HTS Dipole Magnet Demonstrator Designs for the EuCARD-2 5-T 40-mm Clear Aperture Magnet," IEEE Trans. Appl. Supercond., vol. 25, no. 3, Jun. 2015, Art. ID. 4000805 .

[15] T. Mito et al., "Renewal of the control system and reliable long term operation of the LHD cryogenic system," Physics Procedia, vol. 67, 2015, pp. 77-82. 
[16] S. Imagawa et al., "Plan for Testing High-Current Superconductors for Fusion Reactors with a 15 T Test Facility," Plasma and Fusion Research, vol. 10, Feb. 2015, Art. ID. 3405012. 